\title{
The Effect of Therapeutic Horseback Riding on Sensory Processing of Children with Autism
}

\author{
Dr. Mariam Essa. Al-Shirawi, PhD \\ Associate Professor - Intellectual Disability \& Autistic Program \\ Arabian Gulf University, Kingdom of Bahrain \\ Dr. Rehab Hassan Al-zayer, PhD \\ Case Supervisor/Counselor \\ Stepping Stones Center for Autistic Spectrum Disorders, Al Khobar-KSA
}

Doi: 10.19044/esj.2018.v14n15p364 URL:http://dx.doi.org/10.19044/esj.2018.v14n15p364

\begin{abstract}
Cross-sectional quasi- experimental research design was carried out to examine whether the delivering series of therapeutic horseback riding intervention resulted in an enhancement of sensory characteristics required for effective sensory possessing in children with autism for the experimental group compared to the control group. The participants of this study were 16 children with autism recruited from Al-Wafaa Center for Autism Related Disabilities in Bhrain. It was hypothesized that children with autism provided with Therapeutic Horseback riding in a natural setting $(n=8)$ would exhibit improvement in sensory processing compared to children who did not get the treatment $(n=8)$ following an 8- consecutive weeks of therapeutic horseback riding activity. The result of this study indicated that therapeutic horseback riding has a positive impact on sensory profile of children with autism across all sensory dimensions; visual, auditory, smell, tolerance, dehlez, and movement. Further research is needed to allow the use of larger experimental and control samples, and to allow longitudinal studies in order to evaluate the duration of intervention benefits.
\end{abstract}

Keywords: Children with Autism. Pivotal Response Treatment (PRT). Horseback riding. Social Communication

\section{Introduction}

Many children with Autism Spectrum Disorder (ASD) have difficulties processing everyday sensory information, which is indicated the autism diagnosis criteria (DSM-5, 2013). They fall under 'restricted, repetitive patterns of behaviours' descriptors behaviour. Children suffering from autism show hypo or hypersensitivity behaviours in activities such body movements, 
visual, tasting auditory, smelling and tactile. These areas are manifested through seeking or getting rid of any sensory simulation in a particular environment (Ashburner, Ziviani, \& Rodger, 2008). Sensory processing involves sensory adaptation that allow individuals to respond to sensory stimulation in a purposeful manner. Adaptive response is one of the requisite skills needed in the learning process and social interaction of everyday living for children with ASD (Tomchek, Little, \& Dunn, 2015).

Sensory symptoms can be divided into three patterns: hyperresponsiveness, hypo-responsiveness, and sensory seeking conditions. Children who have hyper- responsiveness are easily overwhelmed by normal sensory input that they may react by a "fight, aggressive" or "flight, withdrawal". Children having hypo-responsiveness react to the sensory environment. Hypo-responsiveness is characterized by a diminished degree of responsiveness (as to a physical or emotional stimulus). This implies that these children seek sensory input. The Child may always wants to have something in their hands or appears to crave touch. He or she may not be aware of or bothered by cuts and bruises and may have an excessive love of messy play. The child may also demonstrate self-abusive behaviors such as pinching, biting, or head banging

Regarding children with sensory seeking conditions, they have a prolonged visual inspection of toys also exhibit repetitive behavior when handling objects (Miller et al, 2007). The deficiency in sensory processing hinder individuals with autism ability to give meaning of their experience by analyzing all the information and selecting what to focus on and what to ignore (i.e., listen to the teacher and ignore the noise of other children). In addition, sensory processing deficiency can negatively affects children behaviors. Table 1 below displayed behavioral problems associated with each sensory condition:

Table 1: Common Behavioral Problems Associated with Sensory Conditions

\begin{tabular}{|c|c|c|c|}
\hline & $\begin{array}{c}\text { Hyper- } \\
\text { responsiveness }\end{array}$ & Hypo-responsiveness & Sensory Seeking \\
\hline $\begin{array}{c}\text { Behavioral } \\
\text { Problems }\end{array}$ & $\begin{array}{l}\text { React when being } \\
\text { touched (e.g., } \\
\text { aggression) } \\
\text { Unwilling to take risk } \\
\text { (e.g., refuse to swing in } \\
\text { the playground) } \\
\text { Be anxious in } \\
\text { overstimulating } \\
\text { environment such as } \\
\text { malls, schools, or } \\
\text { playground }\end{array}$ & 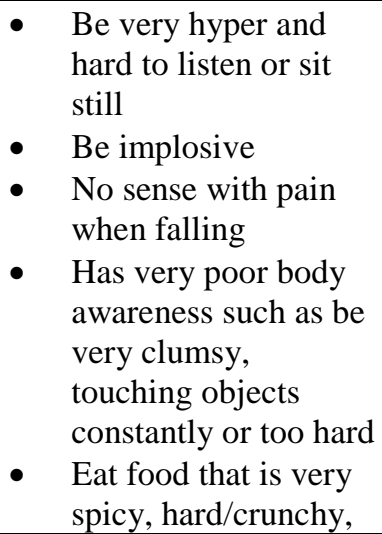 & $\begin{array}{l}\text { - Under sensitive to input, } \\
\text { which may also be } \\
\text { referred to as } \\
\text { hyposensitivity } \\
\text { - } \quad \text { Sensory seekers look for } \\
\text { more sensory } \\
\text { stimulation. Kids may } \\
\text { look clumsy, be a little } \\
\text { too loud or seem to have } \\
\text { "behavior issues." } \\
\text { Have an unusual } \\
\text { tolerance for pain. }\end{array}$ \\
\hline
\end{tabular}




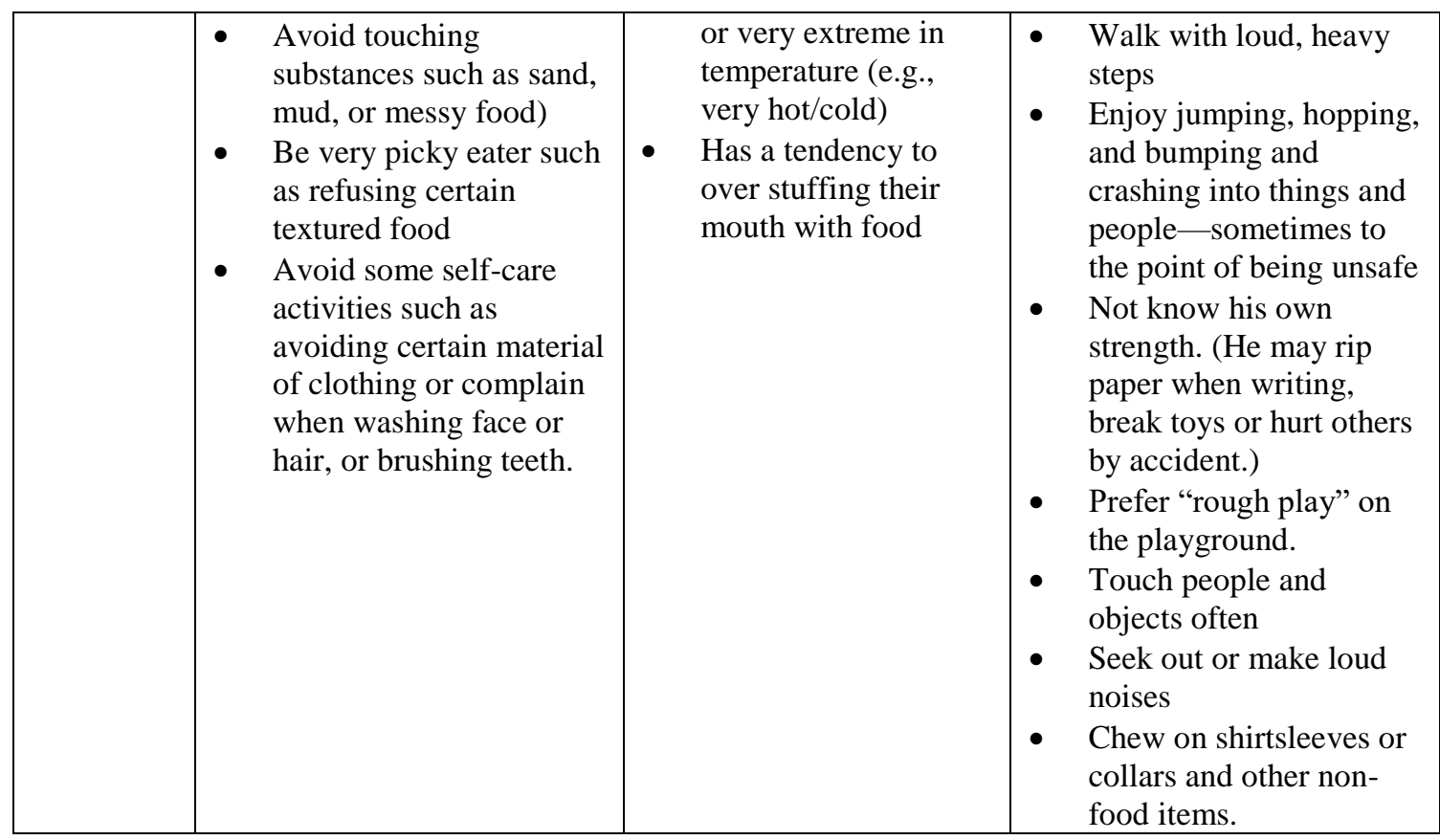

Sensory processing deficit that most children with autism experience affects their emotional well-being, behavior, and social functioning. Children with such deficit cannot select adequate responses to situations and cannot tolerate other environmental stimulations (i.e., noise, smell, taste, or sounds) which causes them to be very anxious, depressed, and isolated (Tomchek et al., 2015). Because of lack of sensory processing, these children experience difficulties in activities such as taking part in group discussions, responding to situations faster and swiftly, processing information and taking in instructions and following it properly. All these deficiencies have an impact on their leaning and playing activities and hinder social participation (Ashburner et al., 2008). It is important to put into consideration efficient and effective intervention techniques when dealing with autism spectrum disorders since these disorders negatively affect socialization process, create communication difficulties and stereotypical behaviors. (Simpson, \& Myles, 2008). Applying strategies that could regulate and facilitate various form of sensory input such as vision, hearing, smell, touch, movement, and internal sensations are highly warranted.

Therapeutic horseback riding has been highly used by occupational therapists as an intervention to regulate sensory inputs. It is among the animalassisted therapies whose use have increased drastically over the last decade (Prothmann \& Fine 2011). Research studies have shown that children who are in the early stages of development and those suffering from autism have a natural interest in animals and other non-human aspects present in their 
surroundings (Melson, 2003). Therapeutic horseback riding has intensified the impact of animal research on the social functioning of children with autism especially with the use of horseback riding in treating posture issues, enhancing balance, and mobility while creating a therapeutic bond between the child suffering from autism and the horse (Martin\& Farnum, 2002). Riding a horse involved many skills such as self-control, attention and focus, sensory integration, and verbal/ non-verbal communication. It also consists of multisensory integration, contact with the horse, psychological stimulations, and social responses. Therapeutic horseback riding is beneficial to children with autism and boosts their social communication skills, improves their attention and sensory integration (Prothmann et al., 2011)

\section{Concept of Horseback Riding Therapeutic}

Therapeutic horseback riding is also referred to as equine therapy. The word Equine is an adjective that determines everything in relation to the horse. This word is of Latin origin "equus" which means "horse" and the suffix "inus" that expresses "belonging" and from the Greek "therapia" which means "medical treatment". There are several definitions that are found on Equine Therapy, of which we will highlight two, as they are relevant for the present work. One of them is from the Establo Therapeutic Foundation (FACET), which in turn is based on the definition of the National Equine Therapy Association (ANDE, Brazil) where:

Equine therapy is a therapeutic and educational method, which has the horse as a mediator / therapeutic facilitator, and its environment as a means within the multidisciplinary approach, in the areas of health, education and riding, seeking the bio-psycho-social development of people with special needs, impediments, disability, disability (WHO 1980) as well as other diseases. (p.18)

The following definition of Assisted Therapy with Horses that delimits it in its entirety, is that used by the National Association of Equestrian Rehabilitation (ANRE), who state that equine therapy refers to: the technique that based on the use of the natural qualities of the horse and used in a perspective of habilitation or integral rehabilitation of the individual - that is, conceiving it as a biopsychosocial being, bearer of one or multiple disabilities - harmoniously integrates elements linked to the areas of health, education and riding, in a necessarily multidisciplinary approach and seeking maximum therapeutic efficacy. (ANRE, 1999: 1)

Alluding to Hernández and Luján (2006), Equine therapy is a physical and psychological therapy which can be used as an alternative rehabilitation treatment for patients with different disabilities, using the horse for this purpose, acting as a complementary method of the conventional rehabilitation techniques (physiotherapy, physiatry, psychomotricity, etc.). According to 
Vives (2004, cited in Morey, 2014): "It is a complementary rehabilitation methodology, designed, executed and evaluated by a specialist technician in which he uses the horse and all its environment to intervene on different areas that make up the integral development of the person "(p.50). This is similar to what Falke (2009) said Equine therapy should be developed with a trained and qualified interdisciplinary team consisting of psychologists, social workers, psychologists, psychiatrists, veterinarians, kinesiologists, physical education teachers, riding instructors. Rehabilitation and habilitation are processes designed to allow people with disabilities to reach and maintain an optimum level of physical, sensory, intellectual, psychological and / or social performance (WHO, 2015). Therefore, Equine Therapy is an intervention strategy that meets all the prerequisite conditions in the application of an equestrian discipline, but where the affective relationship that occurs with the horse is fundamental, to help children with autism in socially adapting and reduce their communication difficulties (Ernst; De la Fuente, 2007). Other researchers such as Falke (2009) state that a horse is like a "co-therapist" that allows a individual, through the intervention, to have more self-confidence, more personality and enhanced personal and group communication skills.

\section{Why the Horse?}

The horse manages to transmit to the man tranquility and security. Since the action of being able to direct the behavior of a being, the size and strength of the horse (whose weight reaches $500 \mathrm{Kg}$ ) generates gratifying emotions. This generates between the horse and the individual, affection and respect (Ernst; De la Fuente, 2007). The movements (or "airs" according to Fernández, 2013) natural of the horse are step, trot and gallop. Being the step that is used within the Equinoterapia, since it produces in the horse and in the individual, a series of simultaneous movements that obtain as a result a threedimensional movement. Each step the horse takes is similar to human walking. This does not appear in the trot and gallop since they are exalted movements, where there is a time where the ground is not touched with any of its parts (Fernández, 2013). On the other hand, one advantage is that it is an animal that moves the individual to a new habitat, because therapy is normally practiced in open spaces, in the open air, in constant interaction with nature, where changes in behavior can be more feasible, and therefore provides a new appreciation of reality (Ernst; De la Fuente, 2007).

In this regard, Fernández (2013) states that therapies with horses give the possibility of changing the environment and being able to leave for a moment the traditional spaces where medical therapies are performed, perform habilitation / rehabilitation from a new perspective in direct contact with nature. Outdoor activities produce pleasant, pleasurable emotions, both the sensation of wind for example and the sun on the skin. They are sources of 
connection with the environment that surrounds us and help us to build a wider image of ourselves and mainly of ourselves. This facilitating environment generates the need to appropriate the new environment, with other people or with the animal, which will affect both the institutions, especially the family.

Hernández and Luján (2006) states that the contact with the horse and the environment where the therapy is developed allows the stimulation of the sense of responsibility and the ability to execute tasks. This helps an individual to achieve a full development and eliminating the concurrence to medical, psychological or psychopedagogical effects. Therefore, the relationship of affection that arises between human-animal within this new habitat is also therapeutic. There is an affective bond produced due to the emotional transfer between a child and the horse. When the bond is created it creates therapeutic interventions which reaches a maximum value and capacity allowing the child to progress (Ernst; De la Fuente, 2007). Gross (2006) lists some of the characteristics of a horse that is needed for this kind of therapy. First, the horse should not be very large, it should be smooth, contain regular movement, have a rectangular shape so that it can perform back riding or twin mount. The therapist sits on the horse behind the individual so that he can align the individual 's posture in the riding process in this technique. Therefore, a muscular horse with resistance is required to be able to work without an albardón and support the weight of two people, as it is in this case.

The back of the horse is the main thing for the therapy to be carried out satisfactorily, therefore the development of the lumbar muscles must be observed with attention. A good horse for this type of therapy is a horse with a calm temperament, which shows sensitivity in helping the individual. Serra, Pérez, Vergara and Viladrich, (2011) say that the characteristics of the horse are an important aspect of the therapy process. Since people should feel safe, so the horse should not be too high to not cause feelings of fear and insecurity, in addition to making it difficult for the therapist to teach correct posture and proper management. Regarding the equine therapy, the rider is placed above his own height adapting to his rounded and mobile back away from the horizontality of the floor, which differs from the stretchers of physiotherapy treatment (Ernst; De la Fuente, 2007). The characteristics that are typical of the horse generate various benefits that occur in the interaction with the individual. They differ from those achieved in conventional therapies where the animal is not used. The individual through Equine Therapy experiences fun, pleasure and joy when riding a horse. Patients highly enjoy the riding process, thus creating a close and deep emotional bond with it (Castillo, s / f). Therefore, Falke (2009) states several advantages based on the threedimensional movements performed by the horse. The movement stimulates the sensory and neuromotor sensitivity of the individual. This allows improving and controlling the balance both dynamic and static. It is obtained 
through control of posture and muscle tone, the control of neuromotor coordination and orientation (temporal space and laterality) and perceptive stimulation attention and concentration.

Maciques (2013) states that equine therapy helps in the rehabilitation in children with ASD; it aids them in improving their motor skills at the neuromuscular, cognitive, psychological and social levels. All this is achieved by taking advantage of the three-dimensional movements of the horse and with its body heat and rhythmic impulses all kinds of alterations are stimulated, helping to develop balance, coordination, social interaction, etc. The child performs different exercises on the horse stimulating certain muscles and joints that develop their fine and thick motor skills. In this way, the stimulation of the sensomotor and neuromotor areas is also accessed.

Maciques (2013) shows the different ways of applying equine therapy in children with ASD. Each one of them fulfills different objectives and techniques. The first one is therapeutic massage. It is done freely and without a saddle. If an espagnolette and a sweatshirt are used so that there is no direct contact with the hair of the animal. What is achieved with this technique is that children with ASD demonstrate greater autonomy and self-confidence. The second one is hippo therapy. It is carried out on the back of the horse and with this technique the transmission of the corporal heat of the horse to the rider is achieved. It develops muscle tone and joints, balance, psychomotor coordination and body symmetry and, on the other hand, the cognitive, communicative and personality levels are favored. The third is therapeutic riding: the horse and all its surroundings are used. With this technique, solutions are sought to the learning difficulties that children with ASD present. Among the effects achieved, the affectivity stands out, both for the horse and for the people around him, the mood, attention equine therapy and concentration. Lastly, there is social and adapted equine therapy. These techniques benefit social and affective relationships, helping to solve the adaptation difficulties of children with ASD.

It is also worth noting the areas in which equine therapy provides benefits in children with ASD. Woolfolk (1985) states that some of the most benefited areas include areas of communication and language. This involves an increase of vocabulary, construction of sentences and phrases, articulation of sentences, improvement and increase of communication and expression, stimulation of oral and written language and improvement in the comprehension of the message. It also enhances psychological and cognitive development. This results in improvement of self-esteem and self-confidence, development of attention capacity, enhancement of the feeling of normality, self-control of emotions and improvement in memory. It also helps in areas of socialization promoting relationships outside the family environment and school, acquisition of new experiences, respect and love for animals. It 
enhances the motor aspects through development of locomotion, laterality, fine and coarse motor skills, regulation of muscle tone, construction of balance and increase of elasticity, speed and strength.

As the equine therapy sessions are carried out, children with ASD improve many aspects. Woolfolk (1985) points out the effects that we can highlight: Increased attention and concentration. Increased confidence and self-esteem. Adaptation to the environment. Decrease in aggressive impulses. Development of verbal and non-verbal communication. Motivation and better social development. In this therapy, it is very important to define the objectives that are to be achieved in the short, medium and long term, in order to be able to verify that the benefits are being met and verified more clearly. The objectives of equine therapy in children with ASD are those of equine therapy plus those specific for autism. Next, they are detailed according to Woolfolk (1985), Gross (2006), Lázaro (2000) and Maciques (2006) who state that the general objectives include: Evaluation of the improvement in social skills. Evaluation of the improvement in communication and language skills. Evaluation of the improvement of the motor area. Evaluation of the improvement of the cognitive and psychological area. Creation of free and autonomous people and the promotion of integration.

Hernández and Luján (2006) are of the opinion that if the practice is consistent, it enables a individual to have an exciting, recreational, healthy exercise where an individual achieves a new improved lifestyle enabling them face their daily lives. Achieving better elasticity, favorable changes in your mood, and thus a better general physical condition. Allowing him to increase his self-esteem and gain more confidence and independence progressively. This high self-esteem will allow the individual integration and greater bond with their environment and with society. Another essential benefit stated by Gross (2009) is that it stimulates the digestive system due to the mobilization of the pelvic belt, as a result of the rhythmic impulses that it manifests, since the proper functioning of the intestines is of vital importance for well-being.

Continuing with some of the benefits of Equine Therapy, the author proposes, among others, those mentioned above psychomotor coordination, flexibility, muscular strength and communication. There are two types of communication: verbal and non-verbal ("analogous" (Gross, 2009). We refer to this, how that gestural communication, where information is received through body signals, such as facial expression, eye contact and different postures. In the case of contact with the equine, non-verbal communication occurs to a greater degree, because it is capable of expressing itself through body gestures. This exchange of information that occurs between the horse and the individual, leads to an even deeper communication, although the latter does not speak, as it is in the case of some patients with autism, cerebral palsy or deaf-mutes. It is the individual who will be putting signifiers to the gestures 
or emotions of the horse, having the possibility of being able to put into words those sensations (Gross, 2006). At the time of performing different activities with the horse such as cleaning, feeding (as a form of gratification), playing its different parts, listening to the different sounds it manifests, increases communication. These cares lead to the relaxation of emotional tensions that mostly lead to anguish and insecurity (Fernández, 2013). Other benefits provided by the Equinotherapy proposed by Orpesa, García, Puente, Matute, 2009 are the correction of behavioral problems (isolation, aggressiveness), decreased anxiety, improved self-control of emotions, exercises memory, among others.

\section{Method}

Cross-sectional quasi- experimental research design was carried out to examine whether the delivering series of therapeutic horseback riding intervention resulted in an enhancement of sensory characteristics required for effective sensory possessing in children with autism for the experimental group compared to the control group.

\section{Participants and Setting}

The participants of this study were 16 children with autism recruited from Al-Wafaa Center for Autism Related Disabilities. Al participants met Autism criteria as an evidence of Gilliam Autism Rating Scale-Second Edition (GARS-2). Parents had to consent to pre-testing, eight weeks of the intervention, and one post testing session. The participants were randomly assigned to their experimental and control groups. The experimental group consisted of 8 children three girls and five boys ranging from 6-10 years of age, while the control group consisted of 2 girls and six boys ranging from 6 10 years old.

Participants in the experimental group received the intervention of therapeutic horseback riding, in a horse stable in the kingdom of Bahrain, for eight consecutive weeks, four times a week for one hour. All pre-test measurement was given to the caregiver in both the experimental and the control group before the intervention sessions were introduced. In addition, post-test measurement of both groups conducted at the completion of 8 weeks integrated interventions.

\section{Measures}

\section{Sensory Profile (SP)}

The Sensory Profile (SP) (Dunn, 1999) was conducted to measure the child's sensory processing abilities. It assesses and evaluates the manner through which a child suffering from autism reacts to sensory systems. These sensory systems include touch, visual, multisensory, vestibular, auditory, and 
oral sensory systems. The main function of the SP is to assess the contribution and significance of sensory processes to the daily activities of a child at preand post-intervention. This measure provides information regarding the sensory systems that may either be leading to shortcomings in the functional performance of a student at home or school. The questionnaire is then completed by the individual and scored by the therapist.

The Sensory Profile is a 125 item, norm-referenced, parent-report questionnaire. The frequency of each and every item is rated on a 5-point Likert scale from $1=$ always $(100 \%$ of the time) to $5=$ never $(0 \%$ of the time). It is categorized into three main categories:

1. The first one is the sensory processing section (which is divided into 6 subgroups that evaluate sensory processing in difference modalities, for example, smell (olfactory), auditory, auditory and touch processing.

2. The second one is the modulation section (which is divided into 5 subgroups showing several combinations of input used in daily life, for example, modulation related to body position movement, modulation of sensory input affecting emotional responses)

3. The last one is the behavioral and emotional section (which is divided into 3 subgroups showing emotional and behavioral responses that might reflect individual's sensory processing abilities e.g. emotional/social responses).

\section{Procedure}

Each child in the treatment group received four days a week, an hour per day of therapeutic horseback riding intervention over the span of 8 consecutive weeks. Different colors, shapes, size horses were randomly assigned to the children participants. Parents were asked to stay with their children in the horse stable for all the training sessions. Prior the intervention sessions, the instructors were provided with brief training on how to handle the children and administering all the informed consent forms. All the children in the treatment group received therapeutic riding sessions. Despite the fact that horse assignments had been initially randomized, several adjustments had to be made based on the size and the weight of a child.

Sessions were divided into four phases as follows:

\section{Setting up (15 m)}

This was the first phase in which the participants had to be familiarized with the altered materials and tools in the stable that was lasted for 15 minutes. The goal of this phase was to reduce the anxiety of the horseback riding experience and be familiar with the environment around them. They were then encouraged to touch the shallow pan of shavings, squeeze textured balls, groom stuffed horses with real tools, ride a mechanical horse; the mechanical 
horse was used as a model for example to introduce the actual training. It also helped to determine what the best method is for each child to mount horses.

\section{Mounting and quit riding}

All participants were required to wear the helmets, horseback riding outfits, and boots. After successful mounting the horses, the participants were guided by their instructors for quite riding around the stable. Participants rode the horses with specific verbal cues, "hand on pommel," "Foot in a stirrup," "1, 2, three up and over", and "Right leg over the saddle." Participants were taken for ten minutes non-stop movement in the horses with no interaction unless necessary. They were encouraged to focus on horse movements to relax, accumulate the sights, smells, and motion of riding a horse.

\section{Actual horseback riding $(20 \mathrm{~m})$}

The duration of this phase was 20 minutes, the children participated in 15 min of riding skills each session, which were specifically designed to stimulate sensory seeking, as well as gross and fine motor domains. Participants were instructed to perform the following skills: direct rein, open guided rein, two-point, and use of proper riding aids (leg, seat, hand and voice), upward and downward transitions (halt/walk/trot, trot/walk/halt), as well as posting at the walk and trot. These activities were designed to target balance and coordination. Once participants had learned to walk, trot, and halt on their horse, they were then asked to verbalize the command at the same time. For those participants who were nonverbal, the instructor and volunteers prompted participants to use basic sign language in order to indicate they understood the command, i.e., place hands side-by-side, palms down, and move each hand up and down to request the horse to walk forward. The participants also took part in a "two point pole" exercise where the participant were instructed to guide the horse over five poles placed on the ground while maintaining his or her position on the horse. This segment of the intervention sought to improve planning and spatial reasoning.

\section{Closure (10 minutes)}

This was the last phase of the intervention that lasted for ten minutes; all participants were instructed to follow instruction such as dismounting the horses, taking off the helmets, feeding and brushing the horses. Different labels were reinforced for example "what are you feeding the horse? "Feed the brown horse" "put the brush in the bucket?" In addition, participants were directed to play with each other, brushing the horse together, riding the same horse together, greetings and saying thank you to the instructors and other children. 


\section{Data Analysis}

The Mann-Whitney U-test, and the asymptotic significance (2-tailed) p-value, was utilized to determine if the intervention led to any improvement in sensory profile across sensory dimensions for the experimental group compared to the control group. A similar test was conducted to assess whether the intervention resulted in any improvement in sensory profile for the experimental pre- and post the intervention across sensory profile dimensions. Also, Cohen's d was used as a measure of effect size to indicate the standardized increase within the experimental group from the pre-test to posttest.

\section{Results}

Concerning the following hypothesis:

An intensive therapeutic horseback riding program will result in an improvement in children's with autism sensory profile across all sensory profile dimensions.

The Ranks table 1 below indicated which group can be considered as having better improvement in sensory profile across all sensory profile dimensions following the intensive therapeutic horseback riding intervention program. Overall; namely, the group with the highest mean rank. In this case, the experimental group had better scores across all sensory profile dimensions except for smell dimension as the data indicated no differences between the experimental and control group following the intensive therapeutic horseback riding program (i.e., auditory dimension is $(\mathrm{M}=12.25)$, and Control group is $(M=4.75)$; visual processing is $(M=11.00)$, and Control group is $(M=6.00)$; touch processing dimension is $(M=11.19)$, and Control group is $(M=5.81)$; oral processing is $(\mathrm{M}=11.62)$, and Control group is $(\mathrm{M}=5.38)$; smell processing is $(\mathrm{M}=8.69)$, and Control group is $(\mathrm{M}=8.31)$; body position processing is $(\mathrm{M}=11.44)$, and Control group is $(\mathrm{M}=5.56)$; endurance/tone processing is $(M=11.19)$, and Control group is $(M=5.81)$; movement processing is $(M=11.88)$, and Control group is $(M=5.12)$. 
Table 1 .Mean Rank for the Experimental and Control Group across all Sensory Processing dimension

\begin{tabular}{|c|c|c|c|c|}
\hline \multicolumn{5}{|c|}{ Ranks } \\
\hline & GROUP & $\mathrm{N}$ & Mean Rank & Sum of Ranks \\
\hline \multirow[t]{3}{*}{ TOTAL_AUDIO_POS } & experimental & 8 & 12.25 & 98.00 \\
\hline & control & 8 & 4.75 & 38.00 \\
\hline & Total & 16 & & \\
\hline \multirow[t]{3}{*}{ TOTAL_VISUAL_POS } & experimental & 8 & 11.00 & 88.00 \\
\hline & control & 8 & 6.00 & 48.00 \\
\hline & Total & 16 & & \\
\hline \multirow[t]{3}{*}{ TOTAL_TOUCH_POS } & experimental & 8 & 11.19 & 89.50 \\
\hline & control & 8 & 5.81 & 46.50 \\
\hline & Total & 16 & & \\
\hline \multirow[t]{3}{*}{ TOTAL_TASTE_POS } & experimental & 8 & 11.62 & 93.00 \\
\hline & control & 8 & 5.38 & 43.00 \\
\hline & Total & 16 & & \\
\hline \multirow[t]{3}{*}{ TOTAL_SMEL_POS } & experimental & 8 & 8.69 & 69.50 \\
\hline & control & 8 & 8.31 & 66.50 \\
\hline & Total & 16 & & \\
\hline \multirow[t]{3}{*}{ TOTAL_DEHLEZ_POS } & experimental & 8 & 11.44 & 91.50 \\
\hline & control & 8 & 5.56 & 44.50 \\
\hline & Total & 16 & & \\
\hline \multirow[t]{3}{*}{ TOTAL_TOLERNCE_POS } & experimental & 8 & 11.19 & 89.50 \\
\hline & control & 8 & 5.81 & 46.50 \\
\hline & Total & 16 & & \\
\hline \multirow[t]{3}{*}{ TOTAL_MOVEMENT_POS } & experimental & 8 & 11.88 & 95.00 \\
\hline & control & 8 & 5.12 & 41.00 \\
\hline & Total & 16 & & \\
\hline
\end{tabular}

As a follow up, the Test Statistics table 2 below indicated that there were significant differences between the scores of experimental and control group in sensory profile across all sensory profile dimensions scores following intensive therapeutic horseback riding intervention. Specifically, the test statistic, $U$ statistic, as well as the asymptotic significance (2-tailed) p- value. From the data in the table 2 below, it can be concluded that sensory profile across sensory dimensions of children with autism in the experimental group was statistically significantly higher than the sensory processing dimensions of the children in the control group at a mean level of $<0.05$, visual processing $(U=12.0, P=.03)$, touch processing $(U=10.5, P=.023)$, oral processing $(U=7.0, P=.007$.$) , body position processing (U=8.5, P=.013$. $)$, 
endurance/tone processing $(U=10.5, P=.023$. $)$, and movement processing $(U=5.0, P=.004$. ).

Table 2 Test Statistics

\begin{tabular}{|c|c|c|c|c|c|c|c|c|}
\hline & $\begin{array}{c}\text { TOTAL_A } \\
\text { UDIO_PO } \\
\text { S }\end{array}$ & $\begin{array}{c}\text { TOTAL_V } \\
\text { ISUAL_P } \\
\text { OS }\end{array}$ & \begin{tabular}{|c} 
TOTAL_T \\
OUCH_P \\
OS
\end{tabular} & $\begin{array}{c}\text { TOTAL_ } \\
\text { TASTE_ } \\
\text { POS }\end{array}$ & $\begin{array}{l}\text { TOTAL_ } \\
\text { SMEL_P } \\
\text { OS }\end{array}$ & \begin{tabular}{|} 
TOTAL_D \\
EHLEZ_P \\
OS
\end{tabular} & $\begin{array}{c}\text { TOTAL_T } \\
\text { OLERNCE } \\
\text { _POS }\end{array}$ & $\begin{array}{c}\text { TOTAL_M } \\
\text { OVEMENT } \\
\text { _POS }\end{array}$ \\
\hline $\begin{array}{c}\text { Mann- } \\
\text { Whitney U }\end{array}$ & 2.000 & 12.000 & 10.500 & 7.000 & 30.500 & 8.500 & 10.500 & 5.000 \\
\hline $\begin{array}{c}\text { Wilcoxon } \\
\text { W }\end{array}$ & 38.000 & 48.000 & 46.500 & 43.000 & 66.500 & 44.500 & 46.500 & 41.000 \\
\hline $\mathrm{Z}$ & -3.169 & $-2.107-$ & -2.278 & $-2.685-$ & -..192- & -2.477 & $-2.275-$ & $-2.859-$ \\
\hline $\begin{array}{c}\text { Asymp. Sig. } \\
\text { (2-tailed) }\end{array}$ & .002 & .035 & .023 & .007 & .848 & .013 & .023 & .004 \\
\hline $\begin{array}{c}\text { Exact Sig. } \\
\text { [2*(1-tailed } \\
\text { Sig. })]\end{array}$ & $.001^{\mathrm{a}}$ & $.038^{\mathrm{a}}$ & $.021^{\mathrm{a}}$ & $.007^{\mathrm{a}}$ & $.878^{a}$ & $.010^{\mathrm{a}}$ & $.021^{\mathrm{a}}$ & $.003^{\mathrm{a}}$ \\
\hline \multicolumn{9}{|l|}{$\begin{array}{l}\text { a. Not } \\
\text { corrected } \\
\text { for ties }\end{array}$} \\
\hline $\begin{array}{l}\text { Grouping } \\
\text { Variable: } \\
\text { GROUP }\end{array}$ & & & & & & & & \\
\hline
\end{tabular}

\section{Consequently, concerning the following hypothesis}

An intensive therapeutic horseback riding program will result in an improvement in children's with autism sensory profile across all sensory profile dimensions.

The Ranks table 3 below indicated which the mean rank between the pre- posttest among children in the experimental group. The table showed that the posttest scores are higher in sensory profile across all sensory profile dimensions following the intensive therapeutic horseback riding intervention program. Overall; namely, the posttest indicated highest mean rank. In this case, the experimental group pst test had better scores across all sensory profile dimensions except for smell dimension as the data indicated no differences between the pre- posttests among experimental following the intensive therapeutic horseback riding program (i.e., pre-test auditory dimension is $(M=4.00)$, and post-test is $(M=0.00)$; visual processing pre-test is $(M=4.93)$, and post-test is $(M=1.50)$; touch processing dimension pre-test is $(M=4.50)$, and post-test is $(M=0.00)$; oral processing pre-test is $(M=4.93)$, and post-test is $(M=1.50)$; smell processing pre-test is $(M=3.62)$, and post-test is $(M=3.25)$; body position processing pre-test is $(M=5.42)$, and post-test is $(\mathrm{M}=1.75)$; endurance/tone processing pre-test is $(\mathrm{M}=4.67)$, and post-test is $(\mathrm{M}=4.00)$; movement processing pre-test is $(\mathrm{M}=4.64)$, and post-test is $(\mathrm{M}=3.50)$. 
Table 3 Mean Rank for the pre-post-tests among children in the Experimental across all Sensory profile dimension

\begin{tabular}{|c|c|c|c|}
\hline & $\mathrm{N}$ & Mean Rank & Sum Rank \\
\hline $\begin{array}{ll}\text { TOTAL_AUDIO_PRE - } & \text { Negative Ranks } \\
\text { TOTAL_AUDIO_POS } & \text { Positive Ranks } \\
& \text { Ties } \\
& \text { Total }\end{array}$ & $\begin{array}{l}7^{\mathrm{a}} \\
0^{\mathrm{b}} \\
1^{\mathrm{c}} \\
8\end{array}$ & $\begin{array}{l}4.00 \\
.00\end{array}$ & $\begin{array}{l}28.00 \\
.00\end{array}$ \\
\hline \begin{tabular}{l} 
TOTAL_VISUAL_PRE - \\
Ranks \\
TOTAL_VISUAL_POS $\quad$ Positive Ranks \\
\\
\multicolumn{1}{c}{ Ties } \\
Total
\end{tabular} & $\begin{array}{l}7^{\mathrm{a}} \\
1^{\mathrm{b}} \\
0^{\mathrm{c}} \\
8\end{array}$ & $\begin{array}{l}4.93 \\
1.50\end{array}$ & $\begin{array}{l}34.00 \\
1.50\end{array}$ \\
\hline $\begin{array}{l}\text { TOTAL_TOUCH_PRE }- \text { Negative } \\
\text { Ranks } \\
\text { TOTAL_TOUCH_POS } \quad \text { Positive Ranks } \\
\\
\begin{array}{c}\text { Ties } \\
\text { Total }\end{array}\end{array}$ & $\begin{array}{l}8^{\mathrm{a}} \\
0^{\mathrm{b}} \\
0^{\mathrm{c}} \\
8\end{array}$ & $\begin{array}{l}4.50 \\
.00\end{array}$ & $\begin{array}{l}36.00 \\
.00\end{array}$ \\
\hline $\begin{array}{ll}\text { TOTAL_TASTE_PRE - } & \text { Negative Ranks } \\
\text { TOTAL_TASTE_POS } & \text { Positive Ranks } \\
& \text { Ties } \\
& \text { Total }\end{array}$ & $\begin{array}{l}7^{\mathrm{a}} \\
1^{\mathrm{b}} \\
0^{\mathrm{c}} \\
8\end{array}$ & $\begin{array}{l}4.93 \\
1.50\end{array}$ & $\begin{array}{l}34.00 \\
1.50\end{array}$ \\
\hline $\begin{array}{ll}\text { TOTAL_SMEL_PRE - } & \text { Negative Ranks } \\
\text { TOTAL_SMEL_POS } & \text { Positive Ranks } \\
& \text { Ties } \\
& \text { Total }\end{array}$ & $\begin{array}{l}4^{\mathrm{a}} \\
2^{\mathrm{b}} \\
2^{\mathrm{c}} \\
8\end{array}$ & $\begin{array}{l}3.62 \\
3.25\end{array}$ & $\begin{array}{l}14.50 \\
6.50\end{array}$ \\
\hline 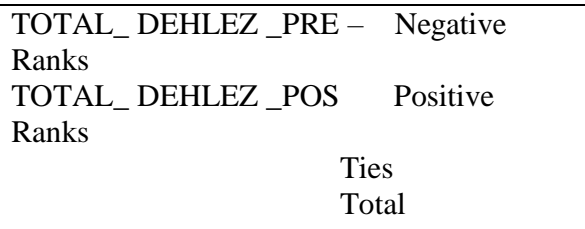 & $\begin{array}{l}6^{\mathrm{a}} \\
2^{\mathrm{b}} \\
0^{\mathrm{c}} \\
8\end{array}$ & $\begin{array}{l}5.42 \\
1.75\end{array}$ & $\begin{array}{l}32.50 \\
3.50\end{array}$ \\
\hline \begin{tabular}{lc} 
TOTAL_TOLERNCE_PRE - & Negative \\
Ranks & \\
TOTAL_TOLERNCE_POS & Positive \\
Ranks & \\
\multicolumn{3}{c}{ Ties } \\
& Total
\end{tabular} & $\begin{array}{l}6^{\mathrm{a}} \\
2^{\mathrm{b}} \\
0^{\mathrm{c}} \\
8\end{array}$ & $\begin{array}{l}4.67 \\
4.00\end{array}$ & $\begin{array}{l}28.00 \\
8.00\end{array}$ \\
\hline $\begin{array}{lcc}\text { TOTAL_MOVEMENT_PRE }- & \text { Negative } \\
\text { Ranks } & & \\
\text { TOTAL_MOVEMENT_POS } & \text { Positive } \\
\text { Ranks } & \\
& \text { Ties } & \\
& \text { Total } & \end{array}$ & $\begin{array}{l}7^{\mathrm{a}} \\
1^{\mathrm{b}} \\
0^{\mathrm{c}} \\
8\end{array}$ & $\begin{array}{l}4.64 \\
3.50\end{array}$ & $\begin{array}{l}32.50 \\
3.50\end{array}$ \\
\hline
\end{tabular}

In addition, Cohen's d a measure of effect size was calculated to measure the effect of profile therapeutic horseback riding on improving 
sensory profile of children with autism in the experimental group using the following equation

\begin{tabular}{|c|c|c|c|}
\hline subscales & Cohen's $d$ & $\begin{array}{c}\text { effect- } \\
\text { size } r\end{array}$ & level \\
\hline AAuditory & 1.60 & 0.62 & Medial \\
\hline VVisual & 1.34 & 0.55 & Medial \\
\hline SSmell & 1.25 & 0.53 & Medial \\
\hline DDehlez & 1.60 & 0.63 & Medial \\
\hline TTaste & 0.68 & 0.32 & Medial \\
\hline MMovement & 1.55 & 0.61 & Medial \\
\hline TTolerance & 1.16 & 0.50 & Medial \\
\hline TTouch & 1.58 & 0.62 & \\
\hline \multicolumn{3}{|c|}{$\mathrm{H} \leq 0.49:$ small } \\
\end{tabular}

\section{Discussion}

This study continues the process of understanding the effects of including a horse in occupational therapy interventions (i.e., on-horse and offhorse activities) on the engagement of young children with ASD. All children made significant improvements, as indicated by an increased proportion of time engaged in activities during equine-assisted occupational therapy sessions compared with baseline. The overall results of this study supported the findings in the literature regarding the efficiency of therapeutic horseback riding on improving the sensory profile of children with autism. This study's results indicated that therapeutic horseback riding has a positive impact on sensory profile of children with autism across all sensory dimensions; visual, auditory, smell, tolerance, dehlez, and movement.

Regarding sensory integration and social functioning, children in the experimental group improved in critical areas such as sensory integration and directed attention. Participants also demonstrated improved social motivation and sensory sensitivity, as well as decreased inattention and distractibility. The observed increase in social functioning may be attributed to a variety of factors. It is possible that exposure to the horse was simply stimulating. The multisensory nature of the therapeutic horseback riding argues that this experience may have been a very stimulating event that was directly associated either with the physical presence or natural movement of the horse. The act of riding the horse may have been perceived as a rewarding stimulus that accounted for higher levels of motivation and social engagement. More specifically, compared to the children with autism in the control group and comparison to the pre-post-test intervention of the experimental group. The observed increase in sensory processing, social functioning, sensory simulation, tolerance, and movement. 
For all participants, the finding regarding social communication tolerance, and sensory input reaction was consistent with the literature, and the research conducted by Ward et al., (2013). Other observed significant changes on participants were being less fixated with object-oriented, ridged routines. At the beginning of the intervention, the children were experiencing fixation difficulties and ridged behaviors that they do not want to smoothly transition between intervention sessions (e.g., mounting/dismounting the horse, or riding another horse color or shape). Towards the end of the intervention, all participants were more flexible with routine changes. This can be attributed to the fact that the horses demand a high level of active and physical movements to encourage the participants to break away their fixation and rigidity with routines (Bass et al., 2009).

Although there are no enough extensive supportive research studies regarding solely therapeutic horseback riding intervention to promote social communication of children with autism (Bass et al., 2009), the findings of the current study have a promising intervention gain. The confrontational point of the current research study was that since a horseback riding is an interactive leisure activity that can be utilized as a high motivator activity to enhance the attention and social skills of the children participants. In this study, horseback riding was utilized as an interactive leisure activity to facilitated social interaction in a natural environment. On the other hands, this activity demands motor learning skills, control skills, and social engagement in which, all in all, contributed to the social functioning gain.

Some precisions have to be considered in further research. Primarily, the relatively small number of children with autism took part in this study limits the generalizations that can be mad regarding the setting and the activity utilized to. It would also be beneficial to measure whether or not children participants have maintained the intervention gain across time. Further studies should increase the length of the intervention to examine whether or not a more intense form of the treatment would yield a greater improvement in sensory processing of children with autism.

\section{Conclusion}

In agreement with Signes (s / f), Maciques (2013), Woolfolk (1985) and Gross (2006) we have been able to verify the equine therapy used in children with autism, it has advantages and benefits at the level of social and language communication and at the cognitive and psychological level. It is demonstrated that contact with the horse provides many stimuli and sensations that help improve these areas. According to Gross (2006), thanks to the relaxation provided by the movement of the horse, the stereotyped movements have been reduced considerably and an increase of concentration is achieved that allows to work calmly, without stress or conflicting episodes. By being 
more relaxed they feel safe in that environment so they are happy and feel happy. It should be noted that, being a natural environment without excessive noise, situations that cause anxiety or fear are reduced.

Regarding the area of social skills and communication and in accordance with Woolfolk (1985) it is very important to note that the improvements obtained have not been altogether high compared to others. Even so, it should be noted that what has been improved is a very important step for children's lives since it will allow them to interact with other people and have the necessary strategies to communicate what they need and to fend for themselves. The most important thing is to have them establish eye contact with the people who address them and keep their eyes when they speak to them. It is important for them to feel safe and good about themselves and what they are doing to keep their motivation and self-esteem high and that they are able to do everything that is proposed to them. In short, and according to Falke (2009) and Woolfolk (1985), equine therapy combined with clinical therapy is a very effective and effective alternative to treat ASD. With it can respond to various needs that children with ASD have and help them to develop as fully as possible.

\section{Limitations}

The main limitation seen in equine therapy is that not all people can afford this type of treatment. Normally these therapies are additional to clinical therapy and are a plus in their cost that many families cannot afford. In our work, the most important limitation has been that the samples have not been randomized. The subjects have been chosen by the specialist to perform this type of therapy and to participate in the research. For its part, the number of subjects has also been very low, in this case eight, since the most favorable thing would have been to have a sample between 10 or 15 subjects to obtain more results in different cases. It should also be noted that the sessions that have been reflected in this research have also been few. Surely, with more than ten sessions it would have been possible to discover many more improvements and advances in these children since the longer treatment would have worked much more in the areas most affected or more difficult to improve. Another of the limitations that we have been able to find is that not all children respond in the same way, nor is equine therapy very useful in all cases. We have seen how each of the patients responds in different ways to the different activities and that not all of them serve all of them.

On the other hand, it was found that some of the children had difficulties in gestural, motor and coordination activities, as well as in muscle tone, which made it more difficult to perform the activities. Finally, this type of therapy has the limitation that not everyone knows them and therefore distrust them. Many families at the beginning of the therapy think that they 
will not be of any use since it is something out of the ordinary, clinically speaking, reason why they are very reticent to realize them. The limitations of our work are to a certain extent the limitations of most of the works consulted and should serve as a guideline for the realization of new contributions.

\section{Future research}

Due to the foregoing, future efforts are needed to allow greater control of intervening variables with more controlled designs, the use of larger experimental and control samples, longitudinal studies to evaluate the duration of benefits, studies with samples of varying degrees of affectation, and studies that allow a variation in the intensity, duration and frequency of the sessions that help to explain the effects of the treatment on the variables of autism. Likewise, further efforts are also needed to understand what are the physical and psychological mechanisms and processes that are put in place in this activity to explain the benefits of therapeutic riding for people with autism.

\section{References:}

1. Alberti, C. (2002). Role of the psychologist in equine therapeutic activity. Area of Social Psychology course of group and institutional psychology. University of the Republic School of Psychology. Indepth seminar: "Research on group and institutional processes in sports".

2. ANDE, B. (s / f.). National Association of Equine therapy. Recovered from Association National of Equine therapy: http://www.equoterapia.org.br/site/index.php.

3. ANRE. (s / f.). National Association of Equestrian Rehabilitation. Retrieved from ANRE: http://anre.org.uy/

4. Arias, V; Arias, B; Morentin, R. (2008). Horse-assisted therapy: new classification proposal, programs for people with intellectual disabilities and good practices. Spanish Magazine on Intellectual Disability. Vol.39, no. 226. Recovered in www.feaps.org/.../344terapia-asistida-por-caballos-nueva-propuesta-de-Epona Association (s / f). Equine therapy and social riding. Multidisciplinary team. Retrieved http://www.epona.cat/fitxers/dossier\%20present.\%20EPONA.pdf

5. Banco de Prevision Social (BPS), (2010). Banco Prevision Social. Retrieved from http://www.bps.gub.uy/5018/apoyo_de_bps_a_la_equinoterapia_para rehabilitacion_de_per sonas_con_discapacidad.html

6. Buil, I; Canals, M. (2012). Retrieved at http://ddd.uab.cat/pub/trerecpro/2011/85707/terasiani.pdf

7. Cardo, M. (s / f). The child and the horse from a psychological 
perspective. Obtained from University of Salvador: http://www.usal.edu.ar/archivos/psico/otros/cardo.pdf

8. Castillo, C. (s / f). Hypnotherapy Center Santa María Polo Foundation. Recovered in http://actividades.uca.es/compromisoambiental/2011/C02/3

9. National Center and Promotion of Rehabilitation (CENAFRE) Ecuestre-URUGUAY (s / f) Retrieved from http://cenafre.blogspot.com.uy/

10. Comin, D. (2011). Assisted Therapy With Animals: Horses. Recovered from

11. http://autismodiario.org/2011/08/02/terapia-asistida-con-animalescaballos/

12. De Quiroga, A. (1990). Approaches and perspectives in Social Psychology. Buenos Aires Editorial five. ISBN-950-9693-03-0. Egg, A; Aguilar, M. (2001). Teamwork. Editorial Progreso, S.A.

13. Ernst, M; De la Fuente, M. (2007). Basic Manual of Hippo therapy: Assisted Therapy with Horses. Spain: The March hare.

14. Fainstein, H. (s / f). Contributions of teamwork for a culture of quality. Retrieved from http://www.leonismoargentino.com.ar/INST439.htm

15. Falke, G (2009). Equine Therapy Clinical, psychological and social approach. Magazine of the Argentine Medical Association, Vol.122. Number 2.

16. Federation of Horses in Education and Therapy International (S.f.) Equine Assisted Activities Retrieved at: http://www.frdi.net/EAA.html

17. Fernández, A. (2013). From equine therapy to equine TAACA. 1st ed. General Roca.

18. Fernández, J., Protesoni, A. (2008) Social Psychology: "Subjectivity and Social Processes- them ".Ed. Psicolibros Universitario- Cony Triun.

19. Garcia, S. (2010). Equinotherapy: A binomial for therapeutic purposes. Veracruz University.

20. Zoo technician Veterinary Doctor. Retrieved on http://cdigital.uv.mx/bitstream/12345678/733/2/Selene\%20Garcia\%2 OSarabia.pdf

21. Gross, E. (2006). Equine therapy: The rehabilitation by means of the horse. Mexico: Editorial Trillas.

22. Gross, E. (2009). Horsemanship and Health. Horseback riding: recreational, sports and Therapeutic activity. Editorial Trillas.

23. Hernández, C; Luján, J. (2006). Equine therapy Holistic rehabilitation. New Horizons. Vol. 5 No. 1. Retrieved at http://www.medigraphic.com/pdfs/plasticidad/prn-2006 / prn061j.pdf 
24. Panamanian Institute of Special Enabling (IPHE), (s / f). Recovered in 25. http://www.iphe.gob.pa/publicaciones/LA\%20EQUINOTERAPIA\% 20REVISTA.pdf

26. Martínez, M. (1992). Participation of the family in the process of rehabilitation of the chronically

27. ill: chronic severe respiratory insufficiency (CRI) and social wellbeing. $\quad$ Retrieved at http://rua.ua.es/dspace/bitstream/10045/5902/1/ALT_01_07.pdf

28. Martínez, R. (2008). Animal-assisted therapy: a new perspective and line of research in attention to diversity. Undivided, Bol. Estud. Inves., $\mathrm{N} \circ$ 9, pp 117-144. ISSN 1579-3141. Recovered in http // DialnetLaTerapiaAsistidaPorAnimales-2777924\% 20 (4) .pdf

29. Morey, F. (2014). Therapeutic intervention with horses. Vision from Psychology. Av.psicol.22 (1). Recovered from http://www.unife.edu.pe/publicaciones/revistas/psicologia/2014/AVA NCES.F.Morey.pdf

30. Muños, B. (2013). Therapy assisted by pets, applied in a geriatric residence in rural areas. University of Murcia. Doctoral Thesis Physiotherapy Department. Retrieved at www.tdx.cat/bitstream/handle/10803/123907/TBMG.pdf?sequence= 1

31. North American Riding for the Handicapped Association (NARHA). North American hippo therapy and therapeutic riding (2001) Retrieved from: www.narha.org

32. World Health Organization (2015). Retrieved at http://www.who.int/disabilities/care/es/

33. Orpesa, P; García, I; Bridge, V; Matute, Y. (2009) Assisted Therapy with Animals as a resource in the rehabilitative treatment. Medisan, (6). Recovered in http://bvs.sld.cu/revistas/san/vol13_6_09/san15609.html

34. Pérez, L; Rodríguez, J; Rodríguez, N. (2008). Equine therapy in the treatment of childhood disability. Archive Medical Archive of Camagüey. Vol. 12, no. 1. Retrieved from http://scielo.sld.cu/scielo.php?script=sci_arttext\&pid=S102502552008000100016

35. Pichón-Riviére, E. (1980). The group process. Psychiatry, a new problem. Recovered in http://www.psicologiagrupal.cl/escuela/E1\%20Proceso\%20Grupal_E PR.pdf

36. Pichón-Riviére, E. (s.f.). Contributions to the didactics of Social Psychology (of The Group Process). Recovered from School of Social Psychology 
http://www.psicosocialdelsur.com.ar/contenido.asp?idtexto=26

37. Pizarro, R. (s / f). The interdisciplinary teams. Retrieved from http://www.binasss.sa.cr/bibliotecas/bhp/cupula/v8n17/art3.pdf

38. Pozner, P. (2000). The manager as manager of school learning. Publisher: Ai- que. Retrieved from https://formacioncontinuaedomex.files.wordpress.com/2012/12/12pozner-pillar.pdf

39. Prado, J. (2003). A practice of Psychologist in Equotherapy. Presbyterian University. Mackenzie Faculty of Psychology. Recovered from http://www.sld.cu/galerias/pdf/sitios/rehabilitacionequino/psicologia.pdf

40. Royal Spanish Academy. (2015). Poliomietis. Spanish dictionary (23rd ed.). Retrieved from http://dle.rae.es/?w=poliomielitis\&m $=$ form $\& \mathrm{o}=\mathrm{h}$

41. Rodríguez, M. (2010). The influence of the family on occupational therapy with hemiplegic patients. Recovered at http://www.revistatog.com/num12/pdfs/original2.pdf

42. Serra, A; San Martin, A; Ruiz, M; Mareca, C. (2011) .Equineotherapy applied to patients with severe mental disorder: presentation of a rehabilitation program and study of a case. Psychosocial rehabilitation; 8 (1 and 2): 37-43.

43. Signes, M. (s / f). Therapy / Activity Assisted with Animals and physical disability. Recovered from http://canismajoris.es/media/pdf/interes/Terapia-asistida-conanimales.pdf

44. Snider, L., Korner-Bitensky, N., Kammann, C., Warner, S. \& Saleh, M. (2007): Horseback Riding as Therapy for Children with Cerebral Palsy. Physical \& Occupational Therapy in Pediatrics, 27(2), 523.

45. Whalen CN, Case-Smith J. (2012) Therapeutic effects of horseback riding therapy on gross motor function in children with cerebral palsy: A systematic review. Phys Occup Ther Pediatr.;32:22942.

46. Silva-Borges MB, Werneck MJ, da-Silva ML, Gandolfi L, Pratesi R. (2011) Therapeutic effects of a horse riding simulator in children with cerebral palsy. Arq Neuro-Psiquiatr (S Paulo). 69:799-804.

47. Underlined. (2012). Free equinotherapy with horses of classifiers in the Prado. Recovered from SUBRAYADO: http://subrayado.com.uy/Site/noticia/18421/equinoterapia- gratis-concaballos-de-classifiers-en-el-prado.

48. National University of Rosario (UNR) (s / f). Equinotherapy from an interdisciplinary approach.

Retrieved at 
http://www.unr.edu.ar/noticia/2897/equinoterapia-desde-un-iprointerdisciplinary

49. Uribe, A; Restrepo, T; Yajaira, D. (2012). How does Equinotherapy benefit people with Down Syndrome? CES Public Health Magazine. ISSN 2145-9932. Volume 3, Number 1, p. 4-10.

50. Valino, C. (2014). The emotional relocation. Clinic and Relational Research. Electronic journal of psychotherapy. Recovered in

51. http://www.psicoterapiarelacional.es/Portals/0/eJournalCeIR/V8N3_2 014/11Vali\%C2\% A40\% $\quad$ 20Perez_El\% 20 remojo\% 20emocional_CeIR\% 20V8N3.pdf

52. Vásquez, J. (s / f). Activities and therapy assisted by animals from the perspective of the Model of Human Occupation. Recovered in

53. http://www.revistas.uchile.cl/index.php/RTO/article/viewFile/17080/ 17817

54. Villalta, V; Ochoa, S. (2007) Therapy facilitated by companion animals as an adjunct rehabilitation program for people diagnosed with Chronic Schizophrenia. Papers of the Psychologist. Vol. 28 (1), pp. 4956. Recovered fromhttp://www.redalyc.org/articulo.oa?id=77828107 